\title{
Type 2 diabetes mellitus in an obese adolescent girl in Bauchi, northeast Nigeria
}

\author{
Muhammad Faruk Bashir', Idris Abiodun Adedeji' ${ }^{1}$, Adamu Sa'idu Adamu1, Yusuf Abdu \\ Misau², Nurrudeen Tanimu Dariya1, Abbas Mohammed Abdulsalam¹ $^{1}$ \\ ${ }^{1}$ Department of Pediatrics, Abubakar Tafawa Balewa University Teaching Hospital Bauchi; ${ }^{2}$ Department \\ of Community Medicine, College of Medical Sciences, Abubakar Tafawa Balewa University Bauchi, Nigeria
}

\begin{abstract}
The prevalence of type 2 diabetes mellitus (T2DM) among children and adolescents is on the rise and this correlates well with increasing prevalence of obesity and overweight worldwide. T2DM was thought to be a disease of the adults, however this has since changed. High index of suspicion is required especially in obese children with family history of type T2DM. To the best of our literature search, till date, no case was reported from Northeast Nigeria. We hereby report a case of newly diagnosed type 2 DM in a 14-year old obese teenage girl, who presented with polyuria, polydipsia and weight loss. Her father is a T2DM patient. She had acanthosis and multiple ovarian cysts. She underwent acute phase of care with insulin before discharge and has remained euglycaemic and clinically state on oral hypoglycaemic agent.
\end{abstract}

\section{Introduction}

Diabetes mellitus (DM) is a group of metabolic disorder characterized by hyperglycemia, resulting from defects in insulin secretion, inaction or both. ${ }^{1}$ T2DM results from progressive loss of insulin secretion on the background of insulin resistance. Etiologically, T2DM is a combination of heterogenous factors with social, behavioural and environmental factors unmasking genetic

Correspondence: Muhammad Faruk Bashir, Department of Pediatrics, Abubakar Tafawa Balewa University Teaching Hospital Bauchi, Nigeria.

Email:mbashirfaruk@gmail.com

Key words: Type 2 diabetes mellitus, obesity, adolescent, Bauchi.

Contributions: the authors contributed equally.

Conflict of interest: the authors declare no potential conflict of interest.

Funding: none.

Received for publication: 13 May 2019.

Accepted for publication: 19 May 2019.

This work is licensed under a Creative Commons Attribution NonCommercial 4.0 License (CC BY-NC 4.0).

CC Copyright: the Author(s), 2019

Licensee PAGEPress, Italy

Annals of African Medical Research 2019; 2:73

doi:10.4081/aamr.2019.73 susceptibility. ${ }^{2}$ The traditional paradigm of T2DM occurring only in adult and type 1 diabetes mellitus (T1DM) only in children no longer holds. ${ }^{3}$ From the mid-1990s, investigators began to observe an increasing incidence of type 2 diabetes mellitus worldwide. T2DM now accounts for about $15 \%$ to $45 \%$ of all newly diagnosed cases of diabetes in children and teenagers. ${ }^{4,5}$ This observation followed a striking increase not only in the prevalence but also the degree of obesity in children and adolescents in many populations. ${ }^{6,7}$ In both developed and developing countries, overweight is, at present, considered the most common health problem facing children. ${ }^{7}$ Race, gender, family history of T2DM in first or second degree relative and clinical signs of insulin resistance, such as acanthosis nigricans, hypertension, and polycystic ovary syndrome (PCOS), are also important risk factors. ${ }^{8} \mathrm{~T} 2 \mathrm{DM}$ is a costly disease with devastating complications and so, screening seems necessary since unrecognised hyperglycaemia would undoubtedly contribute to both microvascular and macrovascular risk in later life. ${ }^{9}$ A few local studies ${ }^{10-12}$ reported T2DM in children, all of which were from the southern part of Nigeria. We, therefore, report the first case of T2DM in an obese teenager from Bauchi, Northeast Nigeria.

\section{Case Report}

We report a case of a 14-year old teenage girl who is Kanuri by ethnicity and presented to our hospital (Abubakar Tafawa Balewa University Teaching Hospital Bauchi, Northeast Nigeria) with three weeks history of polyuria, polydipsia and weight loss as well as a week history of fever, lower abdominal pain and headaches. She was obese and has a family history of obesity (mother and younger sister). She had normal developmental milestones and was doing fairly well in school. However, she was yet to attain menarche (her mother and elder sister both attained menarche at 16 years of age). Her father had T2DM and is on OHA while her mother was a known hypertensive. There was positive history of obesity in the mother as well as the younger sister of our patient. Review of systems was not significant and there were no features of hyperandrogenism (hirsutism, acne etc).

On examination, she was not ill looking, fully conscious, afebrile $\left(37.1^{\circ} \mathrm{C}\right)$ and not in any form of distress. She was, however, moderately dehydrated and had acanthosis nigricans around the axillae and neck regions. She had sexual maturity ratings of II each for breast and pubic hair. Her weight was $91 \mathrm{~kg}$, her height was $180 \mathrm{~cm}$ and her BMI was $27.5 \mathrm{~kg} / \mathrm{m}^{2}$ (SDS +2.08 or 98.1 percentile - obesity). She had abdominal obesity with a waist to hip ratio (WHR) of 0.99 . Her blood pressure was $110 / 80 \mathrm{mmHg}$ (stage I hypertension according to AAP 2017 guidelines). Random blood glucose was $24.1 \mathrm{mmol} / \mathrm{L}$ and urinalysis showed glycosuria ++++ and ketonuria +++ . Fasting lipid panel revealed low HDL cholesterol at $0.78 \mathrm{mmo} / \mathrm{L}$. Complete blood count and renal function test 
were within normal limits. Abdominal ultrasound scan showed bilateral multiple ovarian cysts with some measuring about $2 \mathrm{~mm}$.

The diagnosis of suspected T2DM with mild diabetes ketoacidosis (DKA) in an obese teenager was entertained and we kept in view metabolic syndrome and polycystic ovarian syndrome (PCOS).

DKA was managed with intravenous fluid and insulin infusion at $0.1 \mathrm{IU} / \mathrm{kg} /$ hour. Normal saline was initially used until blood glucose was below $14 \mathrm{mmo} / \mathrm{L}$ when it was changed to $5 \%$ dextrose saline and insulin was reduced to $0.05 \mathrm{IU} / \mathrm{kg} /$ hour. She was also given antibiotics and antimalarial. Forty-eight hours after commencement of treatment, blood sugar had normalized and ketones had disappeared. Insulin was then changed to subcutaneous at 0.75 $\mathrm{IU} / \mathrm{kg} /$ day using basal bolus regimen. Over the following seven days, she had several sessions of diabetes education along with the family members on insulin, diet and exercise; self-injection and self-monitoring of blood sugar; symptoms and management of hypoglycemia; weight reduction via life style modification was especially emphasized. Following discharge and a week later, at the clinic, her blood glucose (BG) chart was noted to range between $7 \mathrm{mmol} / \mathrm{L}$ to $9.2 \mathrm{mmol} / \mathrm{L}$. Insulin was subsequently changed to metformin at $500 \mathrm{mg}$ twice daily. HbA1C came out at $12 \%$. She is presently on regular follow up clinic visit and her BG chart has stabilized at $6-8.4 \mathrm{mmo} / \mathrm{L}$ with a couple of readings above $10 \mathrm{mmol} / \mathrm{L}$ mostly postprandial. There has been no documented hypoglycemia. We are currently working out a plan to have C-peptide and Autoantibodies done as our facility lacks the capacity to carry out such investigations.

\section{Discussion}

Obesity is the hallmark of T2DM. ${ }^{13}$ The increase in the prevalence of obesity in children and adolescents correlates well with increase in the prevalence of T2DM in this age group. Obesity is associated with hyperinsulinism and up to $40 \%$ lower insulin-stimulated glucose metabolism (insulin resistance) compared with nonobese children. ${ }^{7}$ Moreover, there is an inverse relationship between insulin sensitivity and abdominal fat (visceral more than subcutaneous). ${ }^{14,15}$ Our patient was obese $(\mathrm{BMI}=98.1$ percentile $)$ and has abdominal obesity with WHR of 0.99 .

The peak age at presentation of T2DM coincides with midpuberty, hence puberty is thought to play a significant role in its development. ${ }^{9,16}$ Puberty is associated with increased resistance to insulin action owing to the effect of growth hormone as one of the potent counter-regulatory hormones to insulin. Our patient is a 14year old teenage girl with Tanner stage II which coincides with the stage when they have $30 \%$ lower insulin-mediated glucose disposal compare to prepubertal children and with young adult. ${ }^{17}$

Other risk factors for the development of type 2 diabetes in children and teenagers include racial background, family history of T2DM, clinical evidence of insulin resistance, and female gender. ${ }^{5,18}$ Girls are nearly twice as likely to develop T2DM as are boys. Type $2 \mathrm{DM}$ has a disproportionately high prevalence among ethnic minorities (Americans of African, Hispanic, Asian and Indian American descent). Children with T2DM frequently have a family history of the disease. Development of insulin resistance is found to be the main factor in the pathophysiology of T2DM. ${ }^{5,18}$ Some of the clinical and biochemical consequences of insulin resistance include hyperlipidaemia, hypertension and non-alcoholic hepatosteatosis. Acanthosis nigricans and polycystic ovarian syndrome (PCOS), also disorders associated with insulin resistance and obesity, are common in children with type 2 diabetes mellitus. ${ }^{13}$ Many of the aforementioned features were present in our patient. Aside being obese and female, she also had acanthosis, low HDL cholesterol, hypertension and multiple cysts in her ovaries.

Clinically, T2DM can present in one of two forms. Mild form which is usually asymptomatic with hyperglycemia or glycosuria detected during routine medical check-up or the severe form that presents with features of severe insulin deficiency i.e. polyuria, polydipsia, and weight loss with or without ketonuria and ketoacidosis. ${ }^{9,13}$ Our patient presented with features of moderate to severe insulin deficiency and mild form of DKA which was reported to be present in $5-25 \%$ of cases in a particular ethnic group. ${ }^{8}$

Following the diagnosis of DM in children using the established criteria, ${ }^{8}$ classification into type 1 , type 2 or Maturity Onset Diabetes of the Young (MODY) can be made reliably, in most cases, on the basis of clinical presentation and course. ${ }^{13,19}$ Our patient was classified as T2DM because of the preponderance of risk factors favouring T2DM including obesity, family history of T2DM, gender, age at presentation, clinical and biochemical features and conditions associated with insulin resistance. She is also doing quite well on OHA. C-peptide and $\beta$-cell autoantibodies would have established the diagnosis beyond reasonable doubt but these are not available to us.

The ultimate goal of treatment is to decrease the risk of acute and chronic complications associated with DM achievable ideally via normalisation of blood glucose and $\mathrm{HbA1C}$ as well as control of associated comorbidities such hypertension and dyslipidaemia. ${ }^{13}$ The strategies include lifestyle modification, exercise and use of OHA (Metformin) which also has additional benefit of weight reduction. ${ }^{8,20}$ Our patient remained euglycemic and clinically stable on Metformin and lifestyle modification. Where T2DM is not well controlled by diet, exercise and life style modification, or in the early stage of the disease, insulin therapy is crucial for glycemic control. ${ }^{21}$

\section{Conclusions}

T2DM does occur in children and adolescents and can present with comorbidities associated with insulin resistance. Emphasis should be on high index of suspicion and early screening especially in those with risk factors.

\section{References}

1. Pinhas-Hamiel O. Type 2 diabetes mellitus. In: Hochberg Z, ed. Practical Algorithms in Paediatric Endocrinology. 3rd ed. Haifa: S Karger; 2017. pp 108-109.

2. Kiess W, Böttner A, Raile K, et al. Type 2 diabetes mellitus in children and adolescents: a review from a European perspective. Horm Res 2003;59:77-84.

3. Arslanian S. Type 2 diabetes in children: clinical aspects and risk factors. Horm Res 2002;57:19-28.

4. Fagot-Campana A, Pettitt DJ, Engelgau MM, et al. Type 2 diabetes among North American children and adolescents: an epidemiologic review and a public health perspective. J Pediatr 2000;136:664-72.

5. American Diabetes Association. Type 2 diabetes in children and adolescents. Pediatrics 2000;105:671-80.

6. Lobstein T, Frelut ML. Prevalence of overweight among children in Europe. Obes Rev 2003;4:195-200. 
7. Han JC, Lawlor DA, Kimm SY. Childhood obesity. Lancet 2010;375:1737-48.

8. Reinehr T. Type 2 diabetes mellitus in children and adolescents. World J Diabetes 2013;4:270-81.

9. Arslanian SA. Type 2 diabetes mellitus in children: pathophysiology and risk factors. J Pediatr Endocrinol Metab 2000;13:1385-94.

10. Oluwayemi IO. Type 2 Diabetes in a Nigerian Adolescent: Diagnostic and Management Challenges in a resource poor setting. Int J Ped Neo Health 2017;3:74-6.

11. Otaigbe BE, Imafidon EE. Type 2 diabetes mellitus in a Nigerian child: a case report. Afr Health Sci 2011;11:454-6.

12. Anochie IC, Tabansi PN. Type 11 diabetes mellitus in a 15year-old female with congenital hypothyroidism. Port Harcourt Med J 2010;5:105-9.

13. Rosenbloom AL, Silverstein JH, Amemiya S, et al. ISPAD Clinical Practice Consensus Guidelines 2006-2007. Type 2 diabetes mellitus in the child and adolescent. Pediatr Diabetes 2008;9:512-26.

14. Weiss R, Dziura J, Burgert TS, et al. Obesity and the metabolic syndrome in children and adolescents. N Engl J Med
2004;350:2362-74.

15. Taksali SE, Caprio S, Dziura J, et al. High visceral and low abdominal subcutaneous fat stores in the obese adolescent: a determinant of an adverse metabolic phenotype. Diabetes 2008;57:367-71.

16. Reinehr T. Clinical presentation of type 2 diabetes mellitus in children and adolescents. Int J Obes (Lond) 2005;29:S105-10.

17. Pinhas-Hamiel O, Lerner-Geva L, Copperman NM, Jacobson MS. Lipid and insulin levels in obese children: changes with age and puberty. Obesity (Silver Spring) 2007;15:2825-31.

18. Levitsky LL. Type 2 diabetes: the new epidemic of childhood. Presented at the American Academy of Pediatrics Annual Meeting; October 19-23, 2002; Boston, Massachusetts.

19. American Diabetes Association. Diagnosis and classification of diabetes mellitus. Diabetes Care 2013;36:S67-74.

20. Jones KL, Arslanian S, Peterokova VA, et al. Effect of metformin in pediatric patients with type 2 diabetes: a randomized controlled trial. Diabetes Care 2002;25:89-94.

21. Nathan BM. The increase of type 2 diabetes mellitus in children. Minn Med 2007;90:39-43. 